$\begin{array}{ll} & \text { Etnográfica } \\ \text { etnográfica } & \text { Revista do Centro em Rede de Investigação em }\end{array}$

Antropologia

vol. $24(2) \mid 2020$

Vol. $24(2)$

\title{
Lapigados: la diferencia como antídoto al cautiverio de lo Uno
}

Lapigados: a diferença como antídoto para o cativeiro do Um

\section{Gabriel Rodrigues Lopes}

\section{(2) OpenEdition}

\section{Journals}

Edición electrónica

URL: https://journals.openedition.org/etnografica/9188

DOI: 10.4000/etnografica. 9188

ISSN: 2182-2891

\section{Editor}

Centro em Rede de Investigação em Antropologia

\section{Edición impresa}

Fecha de publicación: 1 junio 2020

Paginación: 527-550

ISSN: 0873-6561

\section{Referencia electrónica}

Gabriel Rodrigues Lopes, «Lapigados: la diferencia como antídoto al cautiverio de lo Uno», Etnográfica [En línea], vol. 24 (2) | 2020, Publicado el 31 julio 2020, consultado el 21 enero 2022. URL: http:// journals.openedition.org/etnografica/9188 ; DOI: https://doi.org/10.4000/etnografica.9188

\section{(c) (7) \&}

Etnográfica is licensed under a Creative Commons Attribution-NonCommercial 4.0 International License. 


\section{Lapigados: la diferencia como antídoto al cautiverio de lo Uno}

\section{Gabriel Rodrigues Lopes}

Este artículo describe y analiza el modo de existencia "intensional" de un colectivo de personas con el dom en una región de la caatinga de Bahia (Brasil). El dom singulariza rezadores/as (curandeiros/as y/o feiticeiros), adivinhos/as, vedores y raizeiros, los diferencia entre sí y de sí mismos a lo largo del tiempo. A estos "sabidos" se les atribuye un concepto de adscripción, "lapigado": término nativo engendrado a partir de la relación curandero - espíritu aliado (guia) - etnógrafo, en que la "relación" es anterior a los términos. O sea, la existencia presupuesta de la relación gente-divinidad da sentido a este "encuentro" y permite la "invención" de un concepto en mi presencia, a partir y a causa de mi práctica etnográfica - una variación posible de la práctica nativa de "rastejar" evidencias. Esto porque, según el rezador Capuxo, también soy lapigado, un nativo de la caatinga que actualizó su dom en la ciencia antropológica. Lapigado es un concepto recursivo, intensivo y perspectivista, permite el movimiento de la diferencia (rezador deviene-vedor, por ejemplo), su deriva auto-inscriptiva no elimina la singularidad en nombre del "grupo", ni neutraliza la agencia de alteridades. Por fin, el modo de existencia de estos caatingueiros propone que abandonemos la "certeza" de lo sertanejo a favor de lo "posible" en la antropología lapigada.

PALABRAS CLAVE: lapigado, caatinga, devenir, experiencia, teoría etnográfica.

Lapigados: a diferença como antídoto para o cativeiro do Um • Este artigo descreve e analisa o modo de existência "intensional" de um coletivo de pessoas com o dom na região da caatinga da Bahia (Brasil). O dom singulariza rezadores/as (curandeiros/as e/o feiticeiros), adivinhos/as, vedores e raizeiros e os diferencia entre si e de si mesmos ao longo do tempo. A esses "sabidos" atribui-se um conceito de adscrição, "lapigado": termo nativo engendrado a partir da relação curandeiro espírito aliado (guia) - etnógrafo, em que a "relação" é anterior aos termos. Ou seja, a existência pressuposta da relação gente-divindade dá sentido a esse "encontro" e permite a "invenção" de um conceito em minha presença, a partir e por causa de minha prática etnográfica - uma variação possível da prática nativa de "rastejar” evidências. Isto porque, segundo o rezador Capuxo, também sou lapigado, um nativo da caatinga que atualizou seu dom na ciência antropológica. Lapigado é um conceito recursivo, intensivo e perspectivista, permite o movimento da diferença (rezador devém-vedor, por exemplo), sua deriva autoinscriptiva não elimina a singularidade em nome do "grupo", nem neutraliza a agência de alteridades. Por fim, o modo de existência desses caatingueiros propõe que abandonemos la "certeza" do sertanejo a favor do "possível" na antropología lapigada.

PALAVRAS-CHAVE: lapigado, caatinga, devir, experiência, teoria etnográfica.

LOPES, Gabriel Rodrigues (gabo.sertao@gmail.com) - Instituto de Ciencias Antropológicas, Conicet, UBA, Argentina. 


\section{A MODO DE INTRODUCCIÓN}

En el interior de Bahia, a 450 quilómetros de la capital Salvador y a 80 quilómetros de cualquier ciudad con más de 40 mil habitantes, se encuentran las comunidades rurales de Arapuá, Lagoa do Caldeirão, Volta, Fortuna y el distrito urbano de Pilar, todas en el municipio de Jaguarari. ${ }^{1}$ Esta región se caracteriza por la imponencia de la caatinga, bioma exclusivamente brasilero, de gran biodiversidad y predominante en nueve estados del Noreste de Brasil, con un área de extensión de 850 mil quilómetros cuadrados, ocupando cerca de $12 \%$ del territorio nacional. En la caatinga, el clima es semiárido, con lluvias intermitentes, aunque sea considerada la región semiárida más lluviosa del mundo (en media 200 a $800 \mathrm{~mm}$ anuales), con abundante vegetación xerófila, muy adaptada a las temporadas de sequía y a la elevada evapotranspiración. En esta sabana de Bahia realizo investigaciones etnográficas desde el año 2015, junto con diversos y diferentes rastejadores: curandeiros/as, feiticeiros, raizeiros, vedores y adivinhonas ${ }^{2}$.

Todos reconocen que nacieron con un dom que les permite diferenciarse entre los que "rastejam", o sea, codifican los rastros de animales, personas, lluvia, sequía y/o "ven" agua subterránea (vedores) y modos del fin de las Eras; ${ }^{3}$ los que se transforman en "otro" (árbol, casa de termitas, piedra, madera, cobra, cerdo); y los que "reciben" o "encarnan" guias, en la posesión divina, para realizar curas o los que dialogan con ellos para embrujar. Además, es común escuchar que hay gente que "atina", "estucia", "tem o tino", "faz responso", "se envulta", "se encanta", "vira na besta", "vira bicho", entre otras variaciones de

l Una primera versión de este artículo fue presentada como monografía final inédita en el curso de doctorado: "Introducción a la Antropología Post-Social: Reflexividades, Simetrías y Cosmopolíticas", a cargo del profesor doctor Marcio Goldman (Museu Nacional/UFRJ) en la Universidad Nacional de Córdoba (UNC), en 2018. Agradezco la generosidad del profesor Marcio Goldman por su lectura atenta, sus críticas y sus clases brillantes y provocadoras, bien como al comentarista anónimo por sus sugerencias y a mis compañeros/as del Núcleo de Etnografía Amerindia por el ambiente creativo y estimulante. El trabajo de campo etnográfico que permitió la elaboración del presente manuscrito fue financiado por una beca doctoral del Consejo Nacional de Investigaciones Científicas y Técnicas (Conicet). No está de más aclarar que las limitaciones de este escrito son de mi entera (ir)responsabilidad.

2 Nativos/as con el dom del futuro profético. A través del sueño o de un "pensamiento" saben que un evento sucederá (accidente, muerte, fortuna) porque ya lo vieron prefigurado, han codificado su imagen indicial.

3 Los nativos mayores hacen especulaciones, a partir de relatos de los antiguos y desde sus propias experiencias y la de los demás, en torno a las señales del fin de las Eras. Casi siempre empiezan diciendo: "os mais velhos diziam que vai chegar um tempo em que...", para luego pensar sobre el mundo sin humanos, mundo sin mundo, mundo para pocos humanos, mundo fraccionado, etc. Según los nativos, ahora estamos habitando la Era de humanos con cada vez menos mundo o, como dicen: "é o tempo de muito pasto p'ra pouco rastro". En mi tesis doctoral, en proceso, dedico un capítulo a estas especulaciones metafísicas. 
su "teoría no dialéctica del devenir" (Zourabichvili 2011) que escapan a las posibilidades de este artículo.

El concepto nativo rastejar es utilizado localmente para describir el dom de leer texturas, formas, posición, profundidad, curvas y estado físico-temporal (seco, polvoriento, mojado, húmedo) de las huellas de animales y humanos, para luego indicar su dirección, ritmo, velocidad, compañía, peso, sexo, etc. El rastejar construye otros signos que difieren de aquel inicial, o sea, cuando el rastejador ve un rastro, al mismo tiempo, éste es otra cosa que un rastro, en el momento en el que es "filtrado" por un mundo de imágenes acumuladas por el nativo en sus observaciones y relaciones con la caatinga, desde su propia experiencia, las relatadas por otros, sumadas a las mitologías y a las chamánicas (nivel onírico). De ahí la relación indisociable que encontramos entre rastro-rastejador-rastejado, pues los tres comparten un mismo flujo. Por otro lado, si utilizo el término rastejar como concepto más amplio para dar cuenta de otros modos de relacionalidades del rastejar, es porque la lógica social lo permite y porque cobra sentido para el sentido nativo. A ningún vedor, ${ }^{4}$ rezador (curandeiro y/o feiticeiro), adivinhona o lapigado le ha parecido equivocada la idea de que rastejam venas de agua subterráneas, curas, hechizos, futuros y devenires-minoritarios, respectivamente, aunque así no se expresen. No obstante, están conformes con mi rastejar etnográfico cuando se los comenté.

"Estar dentro de un corto-circuito" es lo que uno experimenta cuando, en vez de encontrar "sertanejos" en el "sertão", se depara con algunos nativos que se llaman a sí mismos y a otros con el nombre de lapigado y con que nadie, hasta donde pude averiguar, afirma que vive en el sertão. Este siempre está más allá: donde no hay gente, sólo hay pasto y animales silvestres. Lapigado ${ }^{5}$ es el nombre de un colectivo social potencial, surgido en el proceso de mi trabajo etnográfico, e interiorizado no sólo como identificación de otros, como lo adscribe el curandero Capuxo a los demás, sino como auto-inscripción, en el caso de él mismo y de su hija, también curandera, y a través de mi contacto con otros nativos con el dom. Es decir, al relatar que Capuxo los llama lapigados les pareció naturalmente lógico que el neologismo para una "pertenencia" colectiva haya sido propuesto por una relación humano-divinidad; si lapigado implica una

4 Vedor es un lapigado que codifica los modos de existencia de diversas venas de agua subterráneas (su trayectoria, ubicación, espesura, profundidad y velocidad potencial), a través de herramientas conductoras de lo "sensible" (horquillas de madera, varillas de metal, hojas, péndulos, tierra, cuerpo). Exponen que la relación vedor-vena es una certeza pragmática en su ontología-dom, en donde lo intensivo es la interacción entre humanos y naturaleza. En tanto aparato de resonancia, su cuerpo es preparado y afectado a través de la acción real de los flujos-venas (sensación de mareos, ahogo, vibración, etc.) o por la relación con sus guias (sueños, intuiciones, "tino").

5 Aclaro que, aunque en el contexto etnográfico el curandero Capuxo hace la declinación de género, aquí prescindo de ella por tomar el término lapigado en su sentido de adscripción a un colectivo social, tal como es común en la etnología indígena (Yanomamis, Wari’, etc.). 
relación humano-extra-humano, el concepto nativo es una operación recursiva y perspectivista.

Estos nativos nacen con un dom y para desarrollar esta potencia inmanente deben componer y fabricar su cuerpo bajo la orientación de guias, ${ }^{6}$ divinidades que se presentan en el mundo ordinario, como una voz, un susurro, un pensamiento, una intuición, en el sueño y en la posesión divina. Dar pasaje a ciertos flujos, a la "força", es también una manera de diferenciarse entre sí. Este flujo es una multiplicidad, y el dom que tiene uno hoy puede devenir "otro". Asimismo, una persona en apariencia sin dones, puede descubrir uno y desenvolverlo, al aceptarlo y actualizarlo, diferenciándose. Lapigado es entonces una categoría nativa que opera como diferenciador o mecanismo para elaborar fronteras entre personas con algún dom y el resto de los habitantes de las comunidades. Pero también funciona como una relación que conecta y desconecta, codifica y diferencia curandeiros, adivinhadores, feiticeiros y vedores. No es regida por un principio de identidad, ella es más bien un espacio nómade que permite mantener la radicalidad de la diferencia. En ese sentido, ellos/as no se otorgan ni la propiedad de sus poderes ni la autoridad para poner en duda los poderes de los otros, aunque algunos digan algo como: "ese rezador no puede rezarme a mí porque soy más fuerte que él”. Lo que les interesa a todos/as es vincularse con sus guias, rezar para curar, seguir a su tino (algo como una intuición, un pensamiento inesperado), relaciones que les dicen "cómo pasa aquí el orden del mundo" (Stengers 2014: 33).

\section{"VIRAR LAPIGADO"}

La palabra lapigado fue "inventada" por el curandero Capuxo y por su guia ante mi presencia y, según él, a causa de ella. ${ }^{7}$ Para él, lapigado es una persona en continuidad cultural con el mundo nativo y, al mismo tiempo, capaz de mantener su alteridad en relación al mismo "colectivo", es decir, a la "diferencia" en torno a los saberes y poderes de cada rastejador. De modo análogo, sucede con una afirmación suya según la cual yo también era lapigado, pues, si fui considerado parte de ese colectivo no fue por mis poderes semejantes a los suyos que,

6 Mantengo la noción nativa "guia", antes que traducirla como espíritu auxiliar o aliado que podría llevar a activar ciertos presupuestos a él asociados, creando, sin querer, bloqueos epistemológicos ante la diferencia. Esto porque, desde el punto de vista etnográfico, el término guia es más indicial que icónico e implica variación, multiplicidad, intensidad virtual. Los guias se llaman a sí mismos como aparelhos, una noción que no permite cerrarla en una representación, sino mantenerla como imagen no capturable, apenas parcialmente codificable. En suma, si los nativos relatan experiencias con una "presencia" que se manifiesta, ¿por qué debería representarla?

7 Recomiendo al lector/a la entrevista realizada con Capuxo en el año 2012, disponible en $<$ https:// www.youtube.com/watch?v=r9_LSa8-OS0 > (última consulta en junio de 2020). 
hasta donde sé, no los tengo, sino por comportarme de modo cultural-moralmente nativo y mantener la alteridad de antropólogo. El conocimiento antropológico que les hago llegar parece ser una variación posible del dom.

Es como si la "cultura antropológica" (representada por mi figura) provocara el efecto de auto-reflexión colectiva entre los nativos con quienes trabajo, un movimiento en marcha de "invención de la cultura", en sentido wagneriano (Wagner 2012). ${ }^{8}$ Luego, es posible que, si el lector/a desea averiguar la eficacia de este "rótulo" en la feria popular, día de jueves, en esta caatinga de Bahia, difícilmente encuentre a alguien que lo lleve a conocer a un lapigado, aunque posiblemente haya uno comprando frijoles o una sandía a su lado. Eso por estarnos ante una definición en "intensio" (Almeida 2013: 23), dada por conceptos no identitarios, sino fluidos, subterráneos y potenciales. Es decir, Capuxo proyecta una multiplicidad y no hay la necesidad de llamar uno a uno a los lapigados a que se presenten a fin de confirmar su membrecía. Si "existir [puede] dejar de ser un presupuesto dado para un colectivo" (Almeida 2013: 24), existir es también un presupuesto dado como invención, en la medida en que nuevos entes extra-humanos y relaciones potenciales con ellos recolocan la cuestión acerca de qué es lo que existe.

Los conceptos mejor situados para dar cuenta del mundo-lapigado y su inherente proceso de diferenciación son los de multiplicidad $^{9}$ y agenciamiento ${ }^{10}$ propuestos por Deleuze y Guattari (1995-1997) y el propio nativo "virar outro". Esto se debe a la potencia anti-sociológica de dichos conceptos, no regidos por principios de identidad, ni de oposición, sino por la "potencia del continuo" (Deleuze 2017), útiles para pensar "procesualidades ontológicas [y] pragmáticas especulativas” (Lima 2018: 122). De hecho, no sería extraño para los nativos que tomemos el término lapigado como "lapidado": algo que fue y debe seguir siendo afectado para develar lo que ya había de modo inmanente.

8 Si la auto-reflexión contextualizada y para ejercicio comparativo es una calidad del pensamiento humano y hacerlo a partir del encuentro con otros colectivos humanos es propio del conocimiento antropológico, todos los humanos ejercitamos el oficio antropológico, seamos académicos o no. De ahí la conclusión de Wagner, de que "no ato de inventar outra cultura, o antropólogo [y el antropólogo nativo] inventa a sua própria e acaba por reinventar a própria noção de cultura” (Wagner 2012: 43).

9 La multiplicidad es "el instrumento principal de un esfuerzo prodigioso para pensar el pensamiento como una actividad otra que la de reconocer, clasificar y juzgar [...] es el modo de existencia de la diferencia intensiva pura" (Castro 2007: 98).

10 En sentido nativo, un agenciamiento es una continuidad, es decir, una sensibilidad relacional que conecta entre si dom, lenguaje y subjetividad y que es animada por el flujo indecible, el poder mismo. Así, una nueva continuidad puede confluir con una anterior, siendo que cada una de ellas exige del lapigado la invención de nuevos códigos. Éste nuevo punto de vista es la diferenciación en una convención que, a diferencia de la "invención” de la cultura de Wagner (2012), no necesitan obviarse entre sí, pues son creatividades ancladas en una continuidad epistémica en la "inestabilidad ontológica" propia de su modo de existencia. En fin, otro mundo que amplía el mundo sertão. 
Desde el punto de vista etnográfico, los "poderes" de los lapigados no deben ser encarados desde la sintáctica (religiosidad, psicología) o semántica (sociología), como recuerda Goldman (2016b), sino por la pragmática de la antropofagia cultural-metafísica (experiencia, "devoração metafísica"). Es como práctica de sentido que su vida nos ofrece conceptos para pensar el sertão, el mestizaje, la identidad, la diferencia y la propia antropología.

$\mathrm{Al}$ evitar el idioma de lo Uno liberamos el espacio para la multiplicidad, la pragmática, la experiencia, lo insólito. En ese sentido, los lapigados ven en la antropología una forma lapigada de existir y actuar. Su ejercicio antropológico reconoce el efecto de ambos oficios sobre el mundo visible, a través de entes alter-materiales (guias y conocimiento antropológico), y exige que un "cuerpo" antropológico sea afectado e implicado por la práctica rastejadora. Por lo tanto, tomando el concepto híbrido de lapigado (Capuxo-guia), extendido no solo a los nativos con dones y poderes en la región, sino a mí mismo, por aquel par gente-divinidad, este artículo es una versión posible de la escritura de un lapigado, expresión de la interiorización de la práctica nativa de rastejar, aquí puesta al servicio de los modos de descripción de mundos, de sentidos, de existencias. Una persona que, por contingencia, actualizó su dom a través del oficio de la antropología. Virar lapigado es virar escritor, traductor de intensidades, de diferencias, de los modos nativos de acceder al conocimiento, a la força (algo como la "fuente" de todos los dones), por intermedio de nociones y conceptos antropológicos y filosóficos, en donde el encuentro entre estos se da a través de mi cuerpo y de mi escritura afectados.

Luego, rastejar en tanto etnografiar es una variación posible en la ontología-lapigado, que aquí intentaré presentar algunas líneas de lectura. Ella misma puede ser leída como una "terceira margem do rio" (Rosa 2001 [1962]) que emerge de la relación entre rastejar materiales etnográficos, teorías antropológicas y conceptos filosóficos a partir del punto de vista del rastejar de "un" lapigado - de lo que estaría en el espectro de lo "posible", desde la perspectiva nativa. Lo que haya logrado y cómo lo haya transmitido al lector/a hace parte de un camino de aprendizaje con mis interlocutores, amigos y parientes. Por eso, probablemente aún estén desequilibrados los instrumentos de codificación de las prácticas de sentido nativas, o sea, que el presente texto aún esté más afectado por la filosofía deleuzo-guattariana que por la filosofía política nativa y su concepto metamórfico y no dialéctico de virar outro. De modo que la presente versión es más reflejo de un antropólogo nativo que de un nativo antropólogo.

Por fin, el eje transversal en todo este trabajo es la siguiente cuestión: ¿qué relación los nativos establecen entre "hallar agua subterránea", "transformarse en piedra", "la posesión divina", "ser inmune a picaduras de culebras", "detener hemorragias", "curar enfermedades", "apagar fuego a distancia”? Para eso, tenemos que mirar hacia la persona lapigada, antes que a un grupo de sertanejos. 


\section{POR UNA TEORÍA ETNOGRÁFICA DE LA IDENTIDAD}

\section{Y DE LA DIFERENCIA}

De acuerdo con Goldman y Castro (2016), si en una "auto-antropología" el nativo realiza una descripción antropológica (con las categorías de esta disciplina) de su "cultura", es porque "sabe" que tiene "cultura"; ya la "antropología reversa” (Wagner 2012) es la descripción antropológica elaborada desde la perspectiva de los nativos que imaginan el mundo de sus "otros" ("los modernos") de un modo diferente al modo en que nosotros nos persuadimos de que es (Wagner 2012, cf. también Goldman y Castro 2016). La diferencia con la antropología del contacto interétnico es que, al contrario de ésta, la antropología reversa no privilegia el punto de vista del observador y sus conceptos extrínsecos a las sociologías nativas. Por ende, este trabajo busca extraer consecuencias de las prácticas de sentido nativas, hecho que es muy diferente de definir, cerrar, estabilizar o, en otras palabras, culturalizar, sociologizar y antropologizar ("la maldición de la tolerancia", diría Stengers 1997). Por el contrario, intento asumir el reto de experimentar con los conceptos-movimiento nativos sin ánimo de cerrarlos, sino de mantenerlos abiertos a la diferenciación.

La contingencia de ser un nativo de la caatinga que devino antropólogo en el momento en que inventé-actualicé la "cultura" en que crecí, de ningún modo me otorga una autoridad epistémica sobre ningún otro/a investigador/a ni tampoco debo ser tomado como porta-voz de mis amigos/as y parientes de la caatinga. Más bien, es necesario devenir nativo en otros agenciamientos: los de diferentes lapigados/as. Mi premisa es que las prácticas de sentido y las conceptualizaciones nativas no necesitan estar ancladas en la tradición de pensamiento occidental para dar cuenta de su realidad y para afectarnos, alterarnos. Con ello, ¿cómo tejer una "teoría etnográfica" (Goldman 2015)? Es decir, ni una teoría nativa, ni una teoría antropológica, sino la relación entre ambas por medio de otra relación, la del etnógrafo con los nativos. Una descripción etnográfica-teórica apoyada en teorías nativas que interpelen e impliquen a la teoría antropológica y, de tal experiencia, él salga afectado, contaminado. Es desde este "pliegue" que buscaré describir qué dirían mis interlocutores sobre determinada cuestión (identidad y diferencia) si quisieran hacerlo.

\section{La máquina nativa de producción de diferencias}

Si los nativos pueden concebir otro mundo acerca del sertão no es sólo porque cada persona puede representar el mundo a su imagen, relativizándolo, sino porque el mundo es diferente porque el cuerpo de los lapigados es el blanco de una elaboración social y colectiva (Seeger, Da Matta y Castro 1979). Como me relataron en varias oportunidades la curandera y adivinhona Giselia y el curandero y vedor Capuxo, uno nace con el dom que se siente en la carne misma, 
en las entrañas y en cada parte de su cuerpo. ${ }^{11}$ Nacer con el dom no es suficiente para saber y poder curar, sino que es preciso ir componiendo un cuerpo (prescripciones alimentarias, sexuales, evitar bañarse, andar descalzo, vivir con animales, entre otras), a partir de las recomendaciones directas de los guias, en la actividad onírica o de vigilia (susurros, ideas, intuiciones). ${ }^{12}$

Tal vez el lapigado más poderoso de la región haya sido Maneca da França, pues era como una figura ideal de vaqueiro, rastejador, vedor, curandeiro y feiticeiro. Aunque él haya ido a casas de religión de matrices africanas en la ciudad de Cachoeira (Bahia), como cuenta su amiga Giselia, fueron sus guias quienes le exigieron el tratamiento de su cuerpo a fin de actualizar o develar lo que ya había como virtualidad. Precisaba oler fuerte, casi no se duchaba, no usaba sandalias, fumaba tabaco en pipa y convivía con animales (como cabras, gallinas, patos y cobras, y a cada uno de éstos le daba un nombre propio) dentro de su casa. Toda esta relación visceral le brindaba a Maneca muchos "poderes", entre ellos: encontrar animales perdidos a distancia, guiarlos cuando nadie podía hacerlo, amansar ganado y caballos bravos, cerrar el cuerpo de ataques externos, adivinhar, curar, "mandar recados" (enviar cobras "mensajeras" para envenenar a un infeliz) y desaparecer "das vistas" de otro al "se virar em outro" (veremos adelante). Como dicen otros rezadores/as, "Maneca era um preto-velho" 13 - no que prescindiera de guias, sino porque con él la metáfora se confunde con la metonimia.

El idioma de la corporalidad es evidente en la brujería nativa. La primera prueba para los parientes de Zé Mauricio de que él había sido hechizado fue cuando adoptó afecciones, modos de ser de un anfibio. Sólo quería comer insectos y ajo, no se paraba, quedaba en cuclillas, no caminaba, saltaba, sus ojos parecían lanzarse de su cara, dando la apariencia de un hombre-sapo. Virarsapo era el hechizo, pero metamorfosearse en sapo era un límite infranqueable que implicaba muerte. Algo parecido les sucedió al raizeiro ${ }^{14}$ Zé y al curandero Sinhô, ambos, ante el riesgo de quedarse moribundos hasta desfallecer,

11 "Del mismo modo que una persona diabética puede haber nacido con su enfermedad", me explicaron Carlos y Giselia.

12 Los guias son maestros, profesores que enseñan a los/las curandeiros/as cómo curar y, de alguna manera, son chamanes, pues les dan força y, en su acción también la adquieren. Un día le pregunté a Dona Vanda por qué un rezador se hace fuerte al rezar, ella me dijo: "É porque fortalecia o meu companheiro né? Meu guia".

13 Es una de las más importantes entidades espirituales del complejo cuadro cosmológico de la umbanda, una de las religiones de matrices africanas en Brasil. Son considerados en la literatura antropológica como un espíritu ancestral negro que ya habitó la Tierra, también como un espíritu de negros esclavizados (Dias y Bairrão 2014; Soares 2013).

14 Como son conocidas las personas que saben prescribir brebajes, infusiones, tés y macerado de hojas y raíces de la caatinga para aliviar síntomas, curar enfermedades, prevenir y evitar el surgimiento de otras. Cuando la receta no es conocida culturalmente, Zé suele decir: "estuciei que cravo de urubu é bom para...". 
se apuraron en impedir que su extensión corporal (una fotografía y una blusa de trabajo, respectivamente) terminara por ser envuelta en el interior de una casa de termitas. Debieron sacarlas de allí antes de que las termitas la encerraran, pues, "cuando las termitas terminan de encerrarlas tú también terminas encerrado", afirman, o sea, el punto de vista de uno sobre el mundo se cierra. La acción humana de meter objetos personales en una casa de termitas desencadena el efecto de transformar lo discreto del mundo ordinario, desde la perspectiva humana, en lo continuo del punto de vista extrahumano, en el caso, de las termitas. Este encuentro pone en contacto, en yuxtaposición, dos existencias posibles, un pliegue que conecta dos lados (Pitarch 2018). Al envolver la extensión corporal de una persona, las termitas separan el humano de su mundo, dan vuelta en el pliegue que nos constituye y nos separa del otro mundo, como recuerda este autor, o sea, una puerta de entrada a otro mundo, a lo de dichos insectos.

En la comunidad de Corredor, no muy lejos de Arapuá, los habitantes relatan que "la policía nunca pudo con Mane do Jove, se cansaban de buscarlo, estaban muy cerca, seguían sus huellas, hasta que desaparecía de la nada". Mane do Jove, el mayor burlador de agentes policiales de la caatinga de Bahia, desaparecía completamente a los ojos de quienes buscaban su forma humana, pero no desaparecía para sí, "se virava numa pedra, árvore ou tôco" (se convertía en piedra, árbol o un pedazo de madera), tal cual lo hacían Maneca, Benavides y Zé Severo. Luego regresaba para contar la historia de su experiencia mientras era "otro". En una de sus fugas, él "se virou numa laje" (se convirtió en una losa), pero de esta vez no salió ileso, algunas personas se subieron a la laje y por arriba caminaron y empezaron a romper rapadura. Para Mane do Jove era su espalda. Llegó a su casa con fuertes dolores y marcas que señaló en su cuerpo a quien ahí está para escucharlo.

Sobre su amigo, nos cuenta el cazador y rastejador Seu Mario:

"Mane do Jove ninguém via. Se ele viesse ali, você: 'ói Mane do Jove onde vem!' Quando você caçava, tava quieto. E se ele não quisesse se envultar assim em... ele quando the via, ele virava num veião [anciano] todo aleijado, e o cabra: 'oxe!, que diabo de velho é aquele que eu nunca vi esse velho aquil’ Aleijado, todo mancando querendo cair”.

Doña Vanda, una ex-curandera de 88 años, cuenta sobre Zé Severo, otro que se virava en casa de termitas:

"O Zé Severo, pai da Nidinha, ele andava no mato e... e... o Calais [del grupo de Lampião] jogou um corte nele e ali... ele deu fé, fez as orações dele e se virou num cupim. Aí, os bandidos passaram, bateram com o fuzil em cima do cupim e só saiu aquela terra, aquela poeira. Quando eles... já fazia 
pedaço [distancia], aí ele correu e foi-se embora e os bandidos ficaram procurando ele lá. Era cupim nas vistas do Calais e dos bandidos".

El movimiento del "virar em" es una multiplicidad rizomática que les permite a estos lapigados actualizar la relación intensiva y molecular del dom en torno a una imagen representacional específica (árbol, pedazo de madera, cerdo, termitas, etc.). La oración proferida antes del "se virar"15 y el dom conforman, juntas, una tecnología evento-corpórea que es a su vez el correlato del enteógeno (rapé, ayahuasca), fundamental en algunos sistemas chamanísticos amerindios para producir conexiones, pliegues y despliegues sobre realidades posibles.

Ya Giselia, sobrina de Mane do Jove, afirma que desde el momento en que decidió asumir su dom, cotidianamente se relaciona con diferentes guias. Éstos le permiten curar muchas enfermedades y adivinhar: puede así saber cuándo sucederá un accidente, morirá algún conocido o qué decisión tomar en las cuestiones financieras. Los vecinos la llaman por teléfono para que les haga alguna cura o llegan sin avisar a su casa. La cocina es donde Giselia y su guia, la preta-velha da mata ${ }^{16}$, a su izquierda, más dialogan, en el sueño es cuándo viaja más lejos y en la posesión divina ("encarnar"), cuando se des-territorializa y se multiplica (ver adelante). De vez en cuando su guia interrumpe la conversación familiar para opinar y aconsejar sobre las finanzas o las relaciones familiares. Sus hijos y su marido saben que lo que vaya a decir, mediada por la rezadora, no puede no ser verdad y eso, más que una transcendencia infalible, se debe a la experiencia de lo sensible y de lo concreto. En estos casos, la conversación toma otro rumbo y cierto mundo se detiene y se derrumba, pero mis amigos saben que hay muchos mundos sobre la caatinga, la diferencia es de qué aparato dispone cada uno para inter-actuar.

15 "Se virar em" o "se envultar em" son conceptos nativos utilizados para dar cuenta de determinadas transformaciones metamórficas de humanos en "otro". Se envultar es una experiencia en el pliegue de lo real, en ella, apenas el sujeto protagonista logra mirar en simultáneo desde dos posiciones-perspectivas (gente | cupim). Al virar "otro" "nas vistas" de alguien, se logra afectar y manejar el punto de vista externo y su acción sobre la "realidad". El lapigado orienta el dom-poder del cual es un maestro para lograr dos acontecimientos paralelos: producir una acción general (evitar un conflicto) y afectar o causar una agencia en otro ("ver" lo que el lapigado desee). En suma, se envultar es una relación que implica una cosmopolítica de la mirada. Todo ello está bastante detallado en uno de los ensayos etnográficos que componen mi tesis de doctorado en antropología social.

16 Es una de las entidades espirituales de la umbanda, considerada por Dias y Bairrão (2014) como un preto-velho desviante, diferenciada de éste. Ya en la cosmología amazónica, según Soares (2013), son seres invisibles con poderes de cura que habitan los ríos y las matas y que viven en el mundo del encante. Estas entidades se comunican por medio de visiones, sueños e incorporaciones. Giselia se refiere a la preta-velha da mata también como del mundo de los "encantados", a diferencia del espíritu - una individualidad de personas fallecidas que se comunican con algunos/as curanderas/os. Todas las veces que pude presenciar, Giselia señalaba que su guia estaba a su lado izquierdo. 
Mientras yo lavaba los platos de la cena, Giselia me relató que un día la fue a visitar una mujer de la ciudad de Petrolina, a $80 \mathrm{~km}$ de su comunidad, que padecía de una enfermedad desconocida e intratable tanto por la medicina como por otros chamanes con quienes estuvo. La mujer tenía una molestia rara en las manos y ya no creía que tuviese cualquier cura. Fue a verla por recomendación de mi tía Carminha, su suegra, que la conoció en un consultorio médico y le recomendó ir a su comunidad y procurar su nuera, pues curaba bien. En esa visita, Giselia "encarnou" por primera vez una anciana indígena. Instantáneamente notó que esta anciana hablaba una lengua completamente desconocida que, al principio, la mujer enferma no pudo entender. Sin embargo, de a poco ella cayó en la cuenta de que la lengua indígena (tal vez Dzubukuá o Kariri, de tronco Macro-jê) que escuchaba era la que hablaba su abuela y que delante de sí ya no estaba la Giselia, sino su pariente fallecida. La anciana pidió una pluma y un papel y comenzó a dibujar el mapa que debería ser seguido por la nieta para hallar la cura, mientras iba explicando a dónde ir y qué senderos de tierra agarrar. Las instrucciones fueron tan precisas que incluso le advirtió que en cierto lugar encontraría un árbol con determinadas características y que allí debería dejar un poco de miel y retirar del tronco algunos pedazos de cáscaras con las que debía hacer la infusión que debería tomar durante quince días.

En la posesión divina Giselia encarna la entidad-guia, a principio desconocida, ya que su gradiente es potencialmente indeterminado. ${ }^{17}$ En el ritual, la agencia sobre el cuerpo y la posición de enunciación deíctica es de la divinidad, que cambia de voz, se mueve de otro modo; los saberes-poderes de cura y adivinatorios se ven potenciados al inimaginable, bien como su conocimiento de la psiquis del atendido que suele sorprenderse por los recados recibidos.

Capuxo actualmente es el único curandero del pueblo de Pilar y, como cuentan por allá, ni siquiera le hizo falta ser "hecho" en una casa tradicional de religión de matriz africana, pues ya nació "hecho". Un día me relató que, hace ya muchos años, cuando él ya rezaba, lo picó una cobra venenosa. Para no morirse, agarró una botella de aguardiente, escupió adentro y tragó unas porciones. Luego pasó treinta días de resguardo sin salir a la calle y sin comer carne de cerdo. A partir de entonces, Capuxo afirma que es "mais cobra que a cobra", pues está inmune a su veneno, puede matarlas con un escupitajo y basta llegar a algún lugar y pronunciar su voz para que las cobras se alejen. Calidad que compartía con su hermano Pedro que, relatan, sobrevivió a decenas de picaduras de cobras, escorpiones y ataques de "raposa espritada" - el zorro, cuando está infectado con el virus de la rabia, ataca ferozmente a cualquier persona que se le cruce el camino.

17 Aunque las entidades espirituales suelen ser nombradas todas como "guías", orixás, espíritos y guias, como la preta-velha da mata, por ejemplo, permanecen diferenciados entre sí. 
Como podría decir Guimarães Rosa (2001 [1962]), en la caatinga aquello que no hay, iacontece! Mane do Jove se convertía en piedra, árbol..., un hombre terminó su vida virando-sapo, Zé y Sinhô casi se murieron cuando las termitas capturaron su extensión corporal. Giselia, Capuxo, Sinhô, Mane do Jove, Maneca y mi abuelo Tenório (especialista en parar hemorragias y apagar incendios, ambos a distancia) se relacionan de modo intenso con alteridades. Algunos, como relata Seu Raimundo, han vivido una "transformación somática" (Castro 2013: 64) cuando empezaron a "vestir" el hábito de outro y a comportarse como Caipora, ${ }^{18} \mathrm{o}$, como Carlos, verse contaminado por la agencia del $z u m b i,{ }^{19}$ una entidad reconocida por su sonido y que produce una inestabilidad ontológica momentánea. Finalmente, Capuxo, su hermano Pedro y Maneca "visten" la piel de serpientes, los primeros son inmunes a sus picaduras y las matan de un escupitajo y el último las envía como correos de la muerte. Todo esto podría ser una colección de anécdotas de la riqueza multicultural brasileña y su estabilidad ontológica que cierra las puertas a la "indeterminación" (Goldman 2015: 654). Sin embargo, ¿qué sucede cuando consideramos seriamente lo que nos dicen?

\section{Gradiente de diferencias}

Las experiencias hasta aquí relatadas nos muestran que hay líneas de fuga que modifican y desterritorializan el segmento rezador/a: una persona tiene determinados poderes de cura y ciertas relaciones ya prescritas con su guia y, en cierto momento, ocurren encuentros inesperados con otras alteridades y/o con nuevos poderes hasta entonces no conocidos (creando nuevas diferencias entre los lapigados). El mismo Capuxo de tanto curar empezó a ver el encuentro de venas de agua subterránea (devenir-vedor) y a poder evaluar también su calidad, indicándoles a quienes le consultan: "pode furar aqui uma cacimba que a água é boa” (agujeree aquí una cisterna pues el agua es buena).

18 Caipora es conocida en la caatinga como "mãe-das-caças", una mujer bonita, rubia e invisible, es la entidad protectora de los animales de caza. Uno de los acuerdos-Caipora implica reciprocidad: el cazador debe ofrecerle tabaco o miel, dejarlo en un árbol y decir "ese tabaco é p'ras Caipora mostrar as caças". De su parte, la "dona-da-mata" no pondrá trabas a la empresa del cazador, o sea, no esconderá la caza, ni lo dejará perdido o lo golpeará, siempre y cuando el cazador cumpla con un segundo acuerdo, el principio de suficiencia (la no avaricia) con relación a las presas. Por otro lado, Caipora puede alterar la realidad sensible humana por su propia realidad sensible extra-humana. Al seguir su sonido, una persona no se cansará de caminar, no tendrá sed, ni hambre y no sentirá el paso del tiempo hasta que se despierta y, asustada, dirá: "Caipora me ideou". Además, la relación de comensalidad con Caipora implica "devoração metafísica", el humano se encanta, desaparecerá "de las vistas" de la humanidad como la conocemos y virará Caipora.

19 Según Carlos, al llegar a la puerta de su casa escuchó un sonido único, agudo, fuerte, lejos. Sabía que se trataba del invisible zumbi y que no podría imitarlo, pero igual quiso probar. Dice que nunca más volverá a hacerlo, pues cuando lo imitó, el sonido se le acercó tanto a la cara que le tomó la razón, dejándole en el piso, completamente trastornado, sin reconocer dónde estaba y qué había sucedido. 
Al cartografiar las relaciones de los/as rezadores/as con sus guias, podemos ver la relación [Yo - "otro"]: ${ }^{20}$

$$
\begin{aligned}
& {[\text { Yo - espíritu }]} \\
& {[\text { Yo - preta-velha }]} \\
& {[\text { Yo - "otro"] }}
\end{aligned}
$$

En general, se aprecia que entre el lapigado y "otro" hay, por un lado, diferencias que tienen que ver con las distancias relativas, pero no constantes e iguales, entre ellos y, por otro, diferencias que responden a la necesidad de crear y mantener dicha diferenciación (distancias diferenciales). Es decir, el rezador/a y los guias (o Mane do Jove y "otro") mantienen distancias proporcionales entre sí (una distancia relativa a la condición de alteridad) que, por la intensidad y la continuidad de las relaciones (efecto de la experiencia), devienen distancias diferenciales entre lapigados ( $\mathrm{y}$ al interior de este propio concepto). En otros términos, "quem garante que, para o vaqueiro, a diferença significativa entre o homem e o gado seja a mesma que existe para com o cavalo?" (Lima 1999: 51). Las distancias diferenciales son líneas de fuga a la sobrecodificación de un aparato de resonancia inmanente que pareciera emitir significados que estabilizarían la relación con la diferencia: tanto conceptual ("todos son guias", aunque diferenciados entre sí), como potencial (cuando la intensidad entre las diferencias y su fuerza molecular de diferenciación tiende a aquietarse, a volverse identidad, lo que nos lleva otra vez al concepto).

Así, aunque haya una detención en el movimiento que singulariza, por ejemplo, un curandero anti-ACV (accidente cerebro-vascular), el motor inmanente de diferencias provoca en este mismo curandero un devenir-minoritario y él pasa a tener otro dom: curandero-alejador de culebras, curandero-vedor y así en continuo, puesto que el devenir, como recuerda Viveiros de Castro, escapa tanto a la imitación y reproducción ("mimesis") cuanto a la memoria y a la historia ("memesis"), él mismo es la "diferencia en la práctica" (Castro 2007: 116).

Espero que, al profundizar sobre la noción de dom, se me haga posible esclarecer el gradiente nativo de diferencias. Giselia afirma que los dones son donados por el territorio donde están (el "mundo") y este gran flujo parece detenerse y concretarse en segmentos específicos: curanderos, vedores, adivinhonas, sueños, susurros, posesiones, especialistas en parar hemorragia, en apagar incendios, en curar cáncer, en cerrar el cuerpo contra cuchillos, balas, hechizos, en sueños chamánicos, en virar "otro", en recibir divinidades nuevas, etc. El dom es como una fuerza indescriptible que se corporiza en personas (lapigados potenciales)

20 Para Capuxo, sus guias se hacen evidentes como "intenciones" que salen de la barriga, como "saberes" en los sueños. 
pero que siempre mantiene un resto, un implícito que permanece huyendo en forma de flujos y potenciales nuevos agenciamientos/continuidades. Es decir, la diferenciación en el mundo convencional lapigado es producido en la experiencia, en los momentos en que ellos/as intensifican sus relaciones con la alteridad: cuantas más curas se hagan, más relaciones sociales se necesitan y más intensas éstas deben ser, dando paso a los flujos y a las intensidades que devienen cuerpo (como muchas veces me dijo Capuxo: "quanto mais rezo mais sei"). Rastejar es diferir. En este sentido, cada persona debería ahondar en la relación con sus guias, "fazendo arreio" o "amansando" (concepto nativo para medir la relación y pensar la diferencia), ${ }^{21} \mathrm{o}$ sea, haciéndoles ofrendas y manteniendo la relación en el tiempo, familiarizándose, lo que les permitirá mantenerse fuertes, conectados y, más adelante, hacer nuevas curas o virar outro.

"Fazer arreio", "curar", "virar" son conceptos-movimiento capaces de mantener la fuerza creativa desterritorializadora de las prácticas y de las formas de vida nativas. ¿Qué imagen nos sería útil para dar cuenta de estos conceptos-movimiento, sin hacerles trabas, sin crear límites-métricos? Quizás sea útil la idea de la menor distancia entre dos puntos distantes entre sí, tal como parece sugerirlo el relato de Giselia, quien me dijo que cierta vez tuvo que ir a Buenos Aires a ayudarme, y la forma más rápida para desdoblarse fue soñando. O sea, trazar una línea como segmento $(c \rightarrow c$ ') no sería lo indicado. Podría ser más útil, por el contrario, pensar en un hoyo astronómico. Imagínese una hoja de papel en blanco con dos puntos en sus extremidades, la menor distancia que conocemos requerida para conectarlos es una línea recta. Sin embargo, para la astronomía y para los lapigados, lo más rápido es doblar la hoja, haciendo coincidir los puntos y hacer un agujero entre ellos. Simultáneamente agujeros negros transversales y tubos sin base que cumplen la función de conexión, en modo de tensión constante, en movimiento, que no entorpecen la relación interior-exterior, pliegue-despliegue, al contrario, permiten y producen el pasaje de líneas de fuga, de creatividades y de "funcionamientos virtuales omnipresentes" (Castro 2014: 347).

Hay una idea de Deleuze (2017: 382-383) que permite adensar el hoyo conducto de los lapigados. Se trata de espacios agujereados inventados por el herrero, un doble (con dos cabezas, una nómada y otra sedentaria) que podía habitar una casa sedentaria como si fuera un yacimiento, pues su especialidad

21 En el fazer arreio, la relación entre diferencias se ve potenciada antes que disuelta, pues la ofrenda realizada a los guias para hacer "amistad" no convierte el nativo en guia, ni transforma a éste en nativo, la diferencia se mantiene y es la condición de la relación. Tampoco hay una transformación del guia en la figura del altruista, al revés, si una buena relación cataliza devenires-minoritarios, el abandono lo entorpece, lo bloquea y el dom puede saltar a un familiar directo - no olvidemos también de la posibilidad de infortunios y enfermedades. Por lo tanto, arriar y relacionarse con los guias intensifican relaciones a un nivel rizomático, no numerable. Conexión de puntos antes que enraizamiento, vinculación entre nativos y alteridades antes que fusión. 
es hacer agujeros. Tal como lo hacen los artistas, mis interlocutores crean agujeros que no son una falta o ausencia de algo, sino espacios y medios de comunicación; un espacio en el que se hace posible encontrar lo que ya hay allí, no como pre-existencia, sino como potencia. En ese sentido, los lapigados con sus agujeros, por un lado, hacen confluir sociológicas amerindias (chamanismo, transformación interespecífica, etc.) y afrobrasileras (posesión divina, "ontologías modulatorias" - donde los guias no existen en estados fijos, $c f$. Goldman 2017). Y, por otro lado, agujerean también el monocultivo del Estado que siembra identidades y previne o echa pesticidas sobre la diferencia que puede brotar. Así, cuando un nativo de la caatinga dice que él, yo y otros somos lapigados, tal información implica una implosión desde adentro del mito nacional de las tres razas y de la identidad como autorreferencia.

Esto porque, una línea "mayor" en las ciencias sociales (la del Estado) los representa como sertanejos, el ejemplo afortunado de la integración armoniosa entre aquellas partes (el indio, el negro y el blanco) que dan forma a la identidad mestiza. ${ }^{22} \mathrm{El}$ sertanejo se encuentra en el polo positivo de las teorías del sincretismo y del mestizaje (Goldman 2017), es decir, es una conquista y debe ser preservado en tanto es un producto original de la nación brasileña. La imagen del sertanejo suele asentarse en retratos de unidad, continuidad, homogeneidad, sincretismo y taxonomías, o sea, en "mestizos" que habitan un territorio "liso", como un desierto (el "sertão"), culturalmente semejantes en tanto productos expelidos por un mortero que mistura "razas" (el "mestizaje") y que estarían a la espera de la salvación por un coronel paternalista o por un nuevo Mesías. ${ }^{23}$ Desde la forma-Estado de pensar (Deleuze y Guattari 1995-1997), que opera por teoremas, esencias y axiomas y suele optar por el esquema negación/oposición/fusión, la diferencia, la heterogeneidad y las variables corren el riesgo de transformarse en eclipses, borrones e identidades.

Sin embargo, tal mezcla absorbe lo que sería "mezcla" para los nativos al concebir la diversidad como la homogeneidad resultante de la relación entre diferencias (Goldman 2017). Siguiendo la crítica de Eduardo Viveiros de Castro (1999), no considero al Estado como una entidad trascendente capaz de ser el espacio natural de análisis sobre la realidad en la caatinga. En este sentido, si no queremos elaborar un discurso desde el Estado y a partir del Estado, es preciso "obviar" (en sentido wagneriano) ${ }^{24}$ el vértice de la identidad sertaneja, puesto que sostener que sus sociológicas, cosmopolíticas, mitologías,

22 Sobre el tema ver Goldman (2017), Kelly (2016), Anjos (2000) y Nascimento (1978).

23 Como dijo Ribeiro (1995: 338), los sertanejos tienen una "religiosidad propensa al mesianismo".

24 Wagner define obviación como un método, "una especie de consumación de la noción hegeliana de dialéctica que termina en síntesis. La diferencia es que con la obviación se obtiene una síntesis y entonces una antisíntesis". En otros términos, "es el estado natural de un símbolo [...], la versión secuencial de la metáfora" (2011: 974-975). 
filosofías para la acción y especulaciones escatológicas son apenas entendibles por la situación de contacto con la sociedad brasilera es muy poco plausible. Los lapigados no podrían ubicarse en la posición de lo Uno: ya sea en el extremo de la identificación o en aquel de la diferencia diferenciada.

La máquina de diferenciación que rige sus relaciones con alteridades no puede terminar en diferencias identificables ("dispersos por naturaleza"). Tampoco su (auto)inscripción como brasileños, o "baianos" o de "tal" pueblo, o incluso lapigados no debe situarlos en una esquina fija, estable. Al conjurar ese "estado de excepción ontológico" (sensu Danowski y Castro 2014) en las teorías del mestizaje y del sincretismo, por medio de los pensamientos y prácticas nativas donde la relación con la diferencia es inmanente, se despliega un mundo sobre otro mundo (sensu Don Juan Matus, en Castaneda 1996 [1972]). Del mismo modo que ocurría con los antiguos Tupí de la costa atlántica, los lapigados se mantienen en un movimiento pendular entre un punto y otro, cuasi-unidad que se ve interrumpida por la dispersión que, a su vez, no llega a cristalizarse (Perrone-Moisés y Sztutman 2010). Es en este sentido que el término colonial sertanejo no sólo resulta infructuoso en tanto desenfoca la diversidad del mundo-caatinga, sino que es un concepto obsoleto. Sin embargo, aparatos ópticos nativos saben hacer focos que exhiben la diferencia.

Al operar como punto de encuentro de la diferencia, los lapigados brindan a sus co-residentes la posibilidad de experimentar indirectamente los infinitesimales agentes que pueblan la caatinga y a ser tomados, ellos mismos, como puntos de vista. Alejándonos de la gramática Estado-céntrica (interesada en los grupos, la identidad, la cultura, la unidad política), parece pertinente estarnos preguntando cómo pensar entonces relaciones y asociaciones que no deseen conformarse como cuerpos políticos desde el punto de vista moderno. Para empezar, no se puede decir que los sertanejos sean una entidad étnica, unidad política o una cultura continua y estable, dentro de la cual estarían, por un lado, los lapigados, como una copia o versión reducida de la primera, y por otro, los sertanejos, una versión, continente adentro, de los criollos de la costa - y éstos, de los brasilindios (Ribeiro 1995). ${ }^{25}$

Con aquella imagen de los agujeros que conectan, sería posible elaborar una nueva "distribución cosmosemiótica entre forma y fondo" (Castro 2014: 321 ) que alterne en la producción de las diferencias. Al hacerlo, se estaría yendo contra cierta cultura antropológica - deudora de la forma-Estado de la filosofía kantiana y de la sociología durkheimiana - que parece tener aversión a la autonomía sociopolítica y a la "autodeterminación ontológica de los pueblos"

25 Para Ribeiro (1995: 270), los brasilíndios eran proto-células neobrasileras ("ni indios ni europeos, ni nadie”) que se multiplicaron y se difundieron en diversos núcleos, aglutinadores y aculturadores, llamados de "islas-Brasil". 
(Castro 2014). Si lo posible también puede ser real o es real porque es posible, lo inverso kantiano, ello no es una duda para los nativos (acá me incluyo como nativo). El antropólogo que considere lo que hace de dado/innato allí como del orden de la "cultura" ve en estas realidades una "falla" y una contradicción inercial, y se equivoca doblemente, (1) pues los guias, los hechiceros, la vestimenta corporal, la transformación interespecífica y la posesión divina corresponden al ámbito de lo "dado" pero, (2) no por serlo están inmunes a la acción humana ya que sus "modos de pensamiento y acción diferenciantes" (Wagner 2012: 249) son un esfuerzo por contra-hacer, por diferenciarse, singularizarse delante de una convención dada (Goldman 2016a).

Sobre ello, recuerda Goldman (2017) que la "mezcla" es como un mecanismo ocular, capaz de desenfocar la diferencia al punto de transformarla en un todo homogéneo o, por el contrario, enfocar con tanto detalle que las diferencias aparecen en toda su intensidad. Por ende, los lapigados pueden, al ser vistos, figurar como un colectivo continuo y uniforme, una totalidad o entidad finita; o, más bien, existir como multiplicidad, que hacen pasar una línea de fuga para crear diferencias (gente-curandeiro-vedor). Es decir, si, por un lado, este corte en el flujo crea resonancias en sus agenciamientos anteriores, afectándolos y haciendo correr cierto límite (un lapigado puede sumar a su viejo agenciamiento-curandero una variación interna y curar nuevas enfermedades), por otro lado, su práctica inmanente de apertura al "otro" les hace cruzar un umbral, inaugurando y agregando al anterior otro agenciamiento ("vedor de agua subterránea", "apagador a distancia de incendios", etc.), sin que uno sea incompatible con otro.

Como decía el cantautor brasilero Cazuza, esta máquina de invención nativa es un "veneno anti-monotonía" que deja correr la diferencia y la habita, pues "mundo" puede ser tomado como hipótesis (sensu Wagner 2012). Ello tiene algo a decir para cierta antropología que busca transformarse a partir de la (contra-)antropología nativa.

\section{REFLEXIONES FINALES}

Una teoría etnográfica exige que estén presentes las experiencias y teorías nativas, así como las ontologías y epistemologías que les son propias, para dar cuenta de determinadas cuestiones en los términos de la antropología (Goldman 2016a). Teniendo en cuenta eso, las prácticas nativas de "curar", "virar", "ver" son formas de traducción, en lenguaje humano dentro de ciertos códigos territoriales, de forças que relacionan y afectan, poderes indecibles que generan efectos en su territorio y su cuerpo-conducto. Dicha força no puede ser enmarcada, deducida, controlada, manipulada de forma directa. Sólo se percibe su existencia por sus efectos, cuando aparece corporizada en las grietas, en los agujeros de un cuerpo en tanto lugar potencial de 
territorialización. ${ }^{26}$ La "sociología molecular" (Tonkonoff 2011) de Gabriel Tarde nos permite detener la atención sobre la inmensa diversidad y complejidad de lo más pequeño, de modo que estas prácticas nativas pueden ser vistas como mutaciones infinitesimales, un inmenso rizoma de relaciones caracterizadas por una multiplicidad de líneas en movimiento que al oponerse (en su sentido positivo de encontrarse) se detienen en un punto o nudo, y cuando no, siguen su tendencia a la diferenciación, a la invención, al devenir.

Los lapigados al mediar, traducir y operar como vehículos de resonancia de la força viven una experiencia de "indeterminación ontológica" (Goldman 2017: 23), ni dados a priori, ni encerrables en una esencia, ni génesis, ni destino. Al producir confluencias, estos nativos exprimen "ontologías modulatorias", donde la continua variación es el modo de su existencia o, diría Goldman, los lapigados "sólo existen en sus modulaciones" (2017: 23). Ellos son el cuerpo-lugar de experiencias y la máquina de composición para la diferencia. Son el cuerpo-devenir inmanente al cuerpo singular que desborda ampliamente la individualidad-persona (yo) que caracteriza al "pensamiento de la representación" occidental (Deleuze 1988). Al traducir esta potencia "infinitesimal" en sus cuerpos, los lapigados codifican flujos descodificados y, a su vez, intensifican las diferencias, dejando correr el flujo inventivo. La transformación de humanos en "otros" (piedra, árbol, sapos), la posesión divina, la desestabilización ontológica por la presencia de Caipora o del zumbi y el dom (de la cura, del hechizo, de ver) son formas de relación intensas, profundas y potenciales con la alteridad - contrasincretismos y contramestizajes, por lo tanto.

A lo largo de este texto he buscado desarrollar la idea de que los lapigados son agenciadores de dos movimientos simultáneos: (1) Cortan el flujo y producen confluencias ( $c f$. Anjos 2017), pues son ellos mismos el territorio de intensidades y multiplicidades donde convergen fuerzas diferentes. Como consecuencia, escapan del conjunto mayoritario del mestizaje (sertanejo) y presentan categorías e ideas fértiles de filosofía de las diferencias. (2) Si Pierre Clastres expresó en su etnografía que los "Aché son lo que hacen", como recuerda Barbosa (2004), la particular especialidad de los lapigados es relacionarse con la diferencia y habitar el lugar del equívoco, zona de potencia, de producción (Deleuze 2017) que les permite fugarse de un potencial conjunto de minoría ("los lapigados"), al devenir-vedor, brujo, etc., y "ser" lo que hacen.

$\mathrm{Al}$ permitir la marcha de la experiencia el "yo" se "minora" 27 para liberar devenires y expandir los límites del molde-ser, y el yo-devenido-otro acompaña

26 Cierta vez, al perforarse un pozo en la marca dejada por un vedor, el agua saltó del suelo y Giselia, muy feliz, dijo que era "um milagre, mas o restante das pessoas só conseguia ver água". Ella entonces la juntó en las manos, frotó en el rostro y en el cuello para ganar força.

27 Minorar es una operación para “[...] imponer un tratamiento menor o de minoración, para extraer devenires contra la Historia, vidas contra la cultura, pensamientos contra la doctrina” (Deleuze citado en Barbosa 2004: 530). 
el flujo decodificado en cuanto cuerpo-multiplicidad. Como afirma Deleuze, "el individuo no puede ser definido sustancialmente [...] es verdaderamente un conjunto de relaciones" (2008: 217), y el "individuado" aparece "cuando se puede determinar en él una longitud y una latitud" (2005: 309). En ese sentido, es en el límite, en las relaciones fronterizas o en las diferentes experiencias con la alteridad, que se inaugura otro umbral y un nuevo agenciamiento. Aquí, se exige no sólo el no-hacer (la desterritorialización de Don Juan Matus) ${ }^{28}$, sino también el contra-hacer (la reterritorialización de Don Roy Wagner 2012) para dar pasaje, por los agujeros de circulación, a las fuerzas de relacionalidades. Es entonces por líneas de fuga que podemos encontrarnos con el modo de existencia de los lapigados, mucho más vinculado a relaciones y diferencias que a criterios de unidad. El devenir de los lapigados se relaciona a la intensidad en sus relaciones con "otros", antes que como extensión o reducción de los sertanejos.

Por fin, como nos recuerda Tarde (2006 [1895]), lo estático es la detención del movimiento, la "identidad" es un momento de la diferencia. Por su "pensamiento de la diferencia" (Deleuze 1988), las prácticas de sentido de los lapigados nos ofrecen, por ende, otra filosofía de la identidad (Anjos 2008).

\section{EPÍLOGO}

Hay otras líneas de fuga de los "modos intensivos de existencias" (Souriau 2017: 107) de los lapigados que no caben en los modos de descripción académicos actuales, no sólo porque las creatividades nativas no pueden, ni deben ser capturadas, sino porque mi antropología, tal vez, aún esté vinculada a una "estrategia de reducción, compactación y traducción de la experiencia en contenidos para artículos" (Taddei 2018:301). Si la alteridad es estratégica y confortable para pensar y elaborar conceptos (Taddei 2018), al explicar, develar y analizar, la antropología social puede, sin desear, anestesiar el pensamiento nativo con su método científico y categorías que, a veces, tienden a buscar el sentido último de las cosas, a explicar demasiado.

En ese sentido, creo que el denominado giro ontológico en la disciplina opera como un "arte del pharmakon" (Stengers 2017: 126), es decir, como un remedio que advierte acerca del peligro de nombrar la diferencia como un malentendido epistémico cuando en realidad el malentendido es ontológico. Como tal, previene la aniquilación de otras formas de pensar y vivir. No obstante, puede ser también un veneno "al asociarse a un imperativo que siempre comisiona a portavoces privilegiados" (Stengers 2017: 137) incapaces de reconocer que el hacer antropológico aún debe "desaprender" el método científico, 
ese "cuerpo" que pretende dar sentido al sentido nativo (Castro 2002), que lo sostiene - ya que hay "desconocidos fundamentales" (Stengers 2014) que sus practicantes todavía no estamos equipados para "ver", ni traducir, apenas dejarse contaminar.

Por ende, el abordaje ontológico y su capacidad de relacionar y comparar diferencias, de crear nuevos conceptos, debe ir aún más allá. Según Viveiros de Castro, si al optar por la alteridad radical, la antropología social pudo, con Lévi-Strauss, hacer la crítica a los "fundamentos metafísicos del colonialismo" y, con el giro ontológico, a los "fundamentos colonialistas de la metafísica" (Castro 2012: 156); la contra-antropología lapigada hace una crítica a lo sensible, a los fundamentos del "cuerpo" del/de la antropólogo/a - que aún "duerme mucho pero sólo sueña consigo mismo" (Kopenawa y Albert 2015: 390) -, al promover una torsión en el "tomar en serio" del giro ontológico. Es decir, si muchos/as antropólogos/as lograron considerar a los nativos seriamente, si su discurso está presente en y afectando el discurso antropológico, entonces: ¿cuándo irán "fazer arreio" con "otro" a fin de afectar sus prácticas y relaciones cotidianas?

Por otro lado, la antropología, como diplomacia, promueve encuentros $\mathrm{y}$ conexiones y es potencialmente un chamanismo, un rizoma formado por relaciones intensivas, técnicas de contra-transcendencias y antiteologías contra la ontología naturalista, materialista, antropocéntrica, siendo así, es capaz de componer otros regímenes de percepciones, un "cuerpo" equipado para el "mundo por venir" (Danowski y Castro 2014), una "experiencia práctica como 'obra por hacer"” (Stengers 2017: 130). Por ende, el antropólogo/a es pasible de ser afectado/a por otros modos de relación con la alteridad, radicalmente distintos de los suyos; puede reactivar vínculos, componer con diferentes modos de existencia, co-fabricar mundos al interior mismo de la diferencia.

Teniendo en cuenta eso, la "antropología post-social" (Castro 2015; Goldman 2016b) es una línea de fuga a aquella antropología social como ciencia del Estado, acostumbrada a ver constancia en las variables, a pensar-actuar de modo estado-céntrico, cartesiano y solipsista. Ella es una "intrusión" que logra desterritorializar creativamente la inercia-segmentar impuesta por el postmodernismo y, en ese movimiento, conectarse con otras antropologías post-sociales, como las contra-antropologías y las antropologías indígenas, por ello, jamás debe conjurar el umbral no-saber trascendental (Goldman 2016a). ${ }^{29}$

29 Si el investigador/a es capaz de reconocer un límite en su modo de descripción del mundo dado por los presupuestos que lleva consigo, se podría, al anticipar este límite, conjurar la emergencia del umbral-no-saber transcendental utilizando la común arrogancia moderna científica de sobrecodificar y ningunear lo que no puede saber y explicar en sus términos y conceptos. Junto con el limite-discontinuidad o limite-equivocación aparece, inevitablemente, el umbral-no-saber, un nuevo agenciamiento que fuerza un cambio radical en el agenciamiento anterior, en los presupuestos, en términos deleuzianos (Deleuze 2017). Por ende, es preciso "obviar" (Wagner 2011) lo conocido para dar [continua] 
De hecho, es preciso crear teorías etnográficas ahí mismo, en el equívoco, en lo desconocido, en la diferencia, en el espacio donde habitan los lapigados desde hace mucho. ¿Y por qué? Pues, porque es en la apertura al "otro", en el encuentro con lo insólito que está el "afuera”, el deseo, el remolino, la máquina de guerra de los/as antropólogos/as para cruzar los límites del pensamiento.

Como diría Clarice Lispector: "eu quero é uma verdade inventada".

cuenta de su gemelo, lo desconocido. A partir de allí, todo es nuevo, conceptos, modos de descripción, códigos, y tal vez sólo sea posible darse cuenta de esto al "prestar atención", a desacelerar nuestras certezas delante del "desconocido fundamental". En esta relación, por supuesto, no se puede saber de antemano a dónde se llegará, sin embargo, como dice Goldman (2016a), el "no-sabemos transcendental” lejos de paralizarnos, sirve como motor de impulsión y, agregaría Wagner (2012), de creación e invención. 


\section{BIBLIOGRAFÍA}

ALMEIDA, Mauro W.B. de, 2013, "Caipora e outros conflitos ontológicos".R@U Revista de Antropologia da UFSCar, 5 (1): 7-28.

ANJOS, José C. Gomes dos, 2000, "Cabo Verde e a importação do ideologema brasileiro da mestiçagem", Horizontes Antropológicos, 6 (14): 177-204.

ANJOS, José C. Gomes dos, 2008, "A filosofia política da religiosidade afro-brasileira como patrimônio cultural africano", Debates do NER, 13: 77-96.

ANJOS, José C. Gomes dos, 2017, "Comentários à mesa redonda 'mestiçagens e (contra) mestiçagens ameríndias e afro-americanas'”. Revista de @ntropologia da UFSCar, 9 (2): 213-217.

BARBOSA, Gustavo, 2004, "A socialidade contra o Estado: a antropologia de Pierre Clastres", Revista de Antropologia, 47 (2): 529-576, disponible en: < https://www.scielo. br/pdf/ra/v47n2/a06v47n2.pdf > (última consulta en junio de 2020).

CASTANEDA, Carlos, 1996 [1972], Viaje a Ixtlán: Las Lecciones de Don Juan. Bogotá, FCE.

CASTRO, Eduardo Viveiros de, 1999, "Etnologia brasileira”, en Sergio Miceli (org.), O que Ler na Ciência Social Brasileira (1970-1995): Antropologia (volume I). São Paulo, Sumaré/ ANPOCS, 109-222.

CASTRO, Eduardo Viveiros de, 2002, “O nativo relativo", Mana, 8 (1): 113-148.

CASTRO, Eduardo Viveiros, 2007, "Filiação intensiva e aliança demoníaca”, Novos Estudos - CEBRAP, 77: 91-126.

CASTRO, Eduardo Viveiros de, 2012, “'Transformação’ na antropologia, transformação da 'antropologia'”, Mana, 18 (1): 151-171.

CASTRO, Eduardo Viveiros de, 2013, La Mirada del Jaguar: Introducción al Perspectivismo Amerindio - Entrevistas. Buenos Aires, Tinta Limón.

CASTRO, Eduardo Viveiros, 2014, "O intempestivo, ainda (posfácio)", en Pierre Clastres, Arqueologia da Violência: Pesquisas de Antropologia Política. São Paulo, Cosac Naify, 299$-366$.

CASTRO, Eduardo Viveiros, 2015, Metafísicas Canibais: Elementos para Uma Antropologia Pós-Estrutural. São Paulo, Cosac Naify.

DANOWSKI, Deborah, y Eduardo Viveiros de CASTRO, 2014, Há Mundo por Vir? Ensaio sobre os Medos e os Fins. Florianópolis, Desterro/Cultura e Barbárie. Instituto Socioambiental.

DELEUZE, Gilles, 1988, Diferença e Repetição. Rio de Janeiro, Graal.

DELEUZE, Gilles, 2005, Derrames: Entre el Capitalismo y la Esquizofrenia, vol. 1.․ Buenos Aires, Cactus.

Deleuze, Gilles, 2008, En Medio de Spinoza. Buenos Aires, Cactus (2. ${ }^{a}$ edición, clases 1$)$.

DeleuZE, Gilles, 2017, Derrames II: Aparatos de Estado y Axiomática Capitalista. Buenos Aires, Cactus.

DeleuZe, Gilles, y Félix GUATTARI, 1995-1997, Mil Platôs: Capitalismo e Esquizofrenia, 2. São Paulo, Editora 34.

DIAS, Rafael de N., y José. F. M.H. BAIRRÃO, 2014, "O caldeirão dos insurgentes: os pretos-velhos da mata”, Memorandum, 26: 168-186.

GOLDMAN, Marcio, 2015, “'Quinhentos anos de contato': por uma teoria etnográfica da (contra)mestiçagem”, Mana, 21 (3): 641-659. 
GOLDMAN, Marcio, 2016a, "Cosmopolíticas, etno-ontologías y otras epistemologías: La antropología como teoría etnográfica”, Cuadernos de Antropología Social, 44: 27-35.

GOldman, Marcio, 2016b, Mais Alguma Antropologia: Ensaios de Geografia do Pensamento Antropológico. Rio de Janeiro, Ponteio.

GOLDMAN, Marcio, 2017, "Contradiscursos afroindígenas sobre mistura, sincretismo e mestiçagem: estudos etnográficos”. Revista de @ntropologia da UFSCar, 9 (2): 11-28.

GOLDMAN, Marcio, y Eduardo Viveiros de CASTRO, 2016, "Marilyn Strathern: uma antropologia em câmera lenta", en Marcio Goldman, Mais Alguma Antropologia: Ensaios de Geografia do Pensamento Antropológico. Rio de Janeiro, Ponteio, 119-152.

KELLY, José A., 2016, Sobre a Antimestiçagem. Florianópolis, Cultura e Barbárie.

KOPEnAWA, Davi, y Bruce ALBert, 2015, A Queda do Céu. Palavras de Um Xamã Yanomami. São Paulo, Companhia das Letras.

LIMA, Tânia Stolze, 1999, "Para uma teoria etnográfica da distinção natureza e cultura na cosmologia juruna”, Revista Brasileira de Ciências Sociais, 14 (40): 43-52.

LIMA, Tânia Stolze, 2018, "A planta redescoberta: um relato do encontro da ayahuasca com o povo Yudjá", Revista do Instituto de Estudos Brasileiros, 69: 1 1 8-136.

NASCIMENTO, Abdias do, 1978, O Genocídio do Negro Brasileiro. Processo de Um Racismo Mascarado. Rio de Janeiro, Paz e Terra.

PERRONE-MOISÉS, Beatriz, y Renato SZTUTMAN, 2010, "Notícias de uma certa confederação tamoio", Mana, 16 (2): 401-433.

PITARCH, Pedro, 2018, "A linha da dobra: ensaio de cosmologia mesoamericana", Mana, 24 (1): 131-160.

RIBEIRO, Darcy, 1995, O Povo Brasileiro: A Formação e o Sentido do Brasil. São Paulo, Companhia das Letras.

ROSA, João Guimarães, 2001 [1962], Primeiras Estórias. Rio de Janeiro, Nova Fronteira.

SEEGER, Anthony, Roberto da MATTA, y Eduardo VIVEIROS DE CASTRO, 1979, "A construção da pessoa nas sociedades indígenas brasileiras", Boletim do Museu Nacional, Série Antropologia, 32: 2-19.

SOARES, Mariana, 2013, Almas e Encantados: Uma Cosmologia sobre o Mundo dos Mortos na Região do Baixo Amazonas. Niterói, Universidade Federal Fluminense, tesis de doctorado.

SOURIAU, Etienne, 2017, Los Diferentes Modos de Existencia: Prefacio de Isabelle Stengers y Bruno Latour. Buenos Aires, Cactus.

STENGERS, Isabelle, 1997, Cosmopolitiques VII: Pour en finir avec la tolérance. París, La Découverte, Le Plessis-Robinson.

STENGERS, Isabelle, 2014, "La propuesta cosmopolítica", Revista Pléyade, 14: 17-41.

STENGERS, Isabelle, 2017, En Tiempos de Catástrofes: Como Resistir a la Barbarie que Viene. Buenos Aires, Futuro Anterior.

TADDEI, Renzo, 2018, “O dia em que virei índio - a identificação ontológica com o outro como metamorfose descolonizadora", Revista do Instituto de Estudos Brasileiros, 69: 289$-306$.

TARDE, Gabriel, 2006 [1895], Monadología y Sociología. Buenos Aires, Cactus.

TONKONOFF, Sergio, 2011 , "Prólogo: sociología molecular", en Gabriel Tarde, Creencias, Deseos, Sociedades. Buenos Aires, Cactus, 11-31.

WAGNER, Roy, 2011 , “' 'O apache era o meu reverso’: entrevista com Roy Wagner”, Revista de Antropologia, 54 (2): 955-978. 
WAGNer, Roy, 2012, A Invenção da Cultura. São Paulo, Cosac Naify.

ZOURABICHVILI, François, 2011, Deleuze, Una Filosofía del Acontecimiento. Buenos Aires, Amorrortu.

Receção da versão original / Original version $2018 / 05 / 15$

Aceitação / Accepted $2019 / 11 / 18$ 